has seen fit, however, to include many other more specialized articles on the different subdivisions of abdominal surgery. For example Borrie writes on cancer of the proximal stomach and oesophagus, Aird on the care of the jaundiced patient, Tanner on ulcer haemorrhage, Daintree Johnson on vagotomy and Denis Browne on abdominal operations in childhood, to mention but a few. Naturally these chapters do not cover the whole field of abdominal surgery and the book is certainly no substitute for standard texts, but it does provide a series of very interesting and readable essays on some of the most important and controversial topics in the surgery of the abdomen. As such it represents a most valuable addition to the surgeon's library, and it will undoubtedly be widely read.

It is set in easily read type, on good paper and is well illustrated and elegantly bound. But it makes a heavy tome and for convenience in handling it might with advantage have been split into two separate volumes dealing with general and special considerations respectively.

$$
\text { J.C.G. }
$$

\section{SYMPTOMS AND SIGNS IN CLINICAL MEDICINE}

By E. Noble Chamberlain, M.D., M.Sc., F.R.C.P• 5th Edition. Pp. viii +480 , with 354 illustrations, I9 in colour. Bristol: John Wright \& Sons, Ltd. 1952. 35 s.

The latest edition of this popular book, while retaining its previous size and 'shape,' introduces several small improvements. Many of the figures are better, some notably. To an already profusely illustrated book more photographs have been added.

This book does not claim to replace either the contact between the patient and his observer or the conventional 'Textbook of Medicine.' To the student who has just entered the wards, this book stands in the same relation to his work as did his illustrated manual of anatomy; just as he had to perform the dissection to expose the underlying parts, so he has to perform the physical examination to disclose the underlying signs, and it is only by assiduously practising the techniques of physical examination that he can with confidence display them. This book gives his valuable help, not only in describing clearly the techniques of physical examination, but in giving him forewarning of what he should expect to find.

Two criticisms should be made. The remarks on the significance of changes in the gastric acidity on page 417 are interpreted with some difficulty; and the student who frequently listens for the third heart sound in vain will not be a whit impressed or encouraged by the remark on page 120 that it is sometimes inaudible. Inaudible sounds lie near the limits of credulity.

For all this, as a compendium of facts, thoughtfully assembled and tastefully displayed, this book has few rivals and no peers.

\section{CANCER IN GENERAL PRACTICE}

By R. W. RAVEN, O.B.E., F.R.C.S., and P. E. $\frac{2}{3}$ Thompson Hancock, F.R.C.P. Pp. ix +265 , $\stackrel{\mathbb{Q}}{\varrho}$ with 71 illustrations. London: Butterworth $\& \frac{C}{c}$ Co. 1952. 30s.

This book is a short systematic account of cancer. There is no doubt that it contains a great number of useful facts and the pathology is very well described. Treatment is fully up to date and therapeutic $\frac{\bar{F}}{\bar{D}}$ methods are lucidly portrayed.

It is felt however, that this book does not live up to its title in that it does not approach the subject of $\tilde{\omega}$ cancer from a general practitioner's angle. $A \vec{\circ}$ chapter on the difficulties of diagnosis in general practice would be useful and also a section on the $\vec{\omega}$ treatment of pre-cancerous conditions would not be out of place. In the chapter on carcinoma of the colon even there is no mention of malignant change 3 . developing in patients with ulcerative colitis, nor isi polyposis coli discussed.

This book is carefully written and should prove useful as a reference book to general practitioners $\omega$ who wish to remain up to date with regard to $N$ treatment.

D.L.B.F.

\section{Garrod, Batten \& Thursfield's DISEASES OF CHILDREN}

(Vols. I and II)

Edited by Alan MoNCRIEF, C.B.E., M. F.R.C.P., and PHILIP Evans, M.D., M.Se., F.R.C.P. Fifth edition. Pp. xii + 1973, with 690 illustrations. London: Edward Arnold $8 \frac{\varrho}{\varnothing}$ Co. 1953. $\quad \& 7$ the set.

Although the new edition of this well-known $\overrightarrow{0}$ textbook is published only six years after the first 3 volume of the previous edition, there is a great? deal of new material and revision of old material in? its pages. Happily both volumes of the present edition have been published simultaneously, thus 3 avoiding a defect in the fourth edition.

Several entirely new chapters have been included 3 in this edition; there are those on the causes of congenital malformations, on growth and develop- $\frac{0}{3}$ ment, drug treatment, Kwashiorkor, endocrine disorders, the alimentary tract and on congenitalo heart disease. The general layout of the book has $>$ not been materially altered in this edition, but the inclusion of new articles and the expansion of existing ones has considerably increased its size. ON

In a work of this size, with 50 contributors, then level of each chapter obviously cannot be uniform. N The following chapters appeared to the reviewer ${ }_{\sigma}^{\omega}$ to warrant particular mention. That on the causes? of congenital malformations, by J. P. M. Tizarde introduces several recent observations on this subject and seems particularly worthy of merit for $\stackrel{?}{+}$ its critical survey of the problem of maternalo rubella and congenital deformities in the newborn. The new section on growth and development, by R. S. Illingworth is excellent, and that on water 